\title{
Acute-phase protein $\alpha-1$-acid glycoprotein is negatively associated with feed intake in postpartum dairy cows
}

\author{
W. E. Brown, ${ }^{1} \odot$ M. Garcia, ${ }^{1} \odot$ L. K. Mamedova, ${ }^{1,2} \odot$ K. R. Christman, ${ }^{1}$ M. G. Zenobi, ${ }^{3}$ C. R. Staples, ${ }^{3} \odot$ \\ B. M. Leno, ${ }^{4}$ (D) T. R. Overton, ${ }^{4}$ (D) B. K. Whitlock, ${ }^{5}$ (D) J. A. Daniel, ${ }^{6}{ }^{(1)}$ and B. J. Bradford ${ }^{1,2 *}{ }^{(D)}$ \\ ${ }^{1}$ Department of Animal Sciences and Industry, Kansas State University, Manhattan 66502 \\ ${ }^{2}$ Department of Animal Science, Michigan State University, East Lansing 48824 \\ ${ }^{3}$ Department of Animal Sciences, University of Florida, Gainesville 32608 \\ ${ }^{4}$ Department of Animal Science, Cornell University, Ithaca, NY 14853 \\ ${ }^{5}$ College of Veterinary Medicine, University of Tennessee, Knoxville 27996 \\ ${ }^{6}$ Department of Animal Science, Berry College, Mount Berry, GA 30149
}

\section{ABSTRACT}

$\alpha$-1-Acid glycoprotein (AGP) is an acute-phase protein that may suppress dry matter intake (DMI), potentially by acting on the leptin receptor in the hypothalamus. Our objectives were to characterize plasma AGP concentration and associations with DMI during the transition period, and to determine the utility of AGP to identify or predict cows with low DMI. Plasma samples $(n=2,086)$ from 434 Holstein cows in 6 studies were analyzed on $\mathrm{d}-21,-13 \pm 2,-3,1,3,7 \pm$ $1,14 \pm 1$, and $21 \pm 1$ relative to parturition. A commercially available ELISA kit specific for bovine AGP was validated, and 2 internal controls were analyzed on each plate with interplate variation of 15.0 and $17.3 \%$, respectively. Bivariate analysis was used to assess the relationship between AGP and DMI. For significant associations, treatment(study) was added to the model, and quadratic associations were included in the model if significant. Plasma AGP concentration $( \pm \mathrm{SEM})$ increased from $213 \pm 37.3 \mu \mathrm{g} / \mathrm{mL}$ on $\mathrm{d}-3$ to $445 \pm 60.0$ $\mu \mathrm{g} / \mathrm{mL}$ on d 14. On d 3, AGP was associated negatively with DMI in a quadratic manner for wk 1 and wk 2 and linearly for wk 3. Day 7 AGP was associated negatively with DMI in a quadratic manner for wk 2 and linearly for wk 3. Similarly, d 14 AGP was negatively associated with DMI for wk 3 and wk 4. As d 3 AGP concentration increased over the interquartile range, a calculated $1.4(8.5 \%), 0.5(2.7 \%)$, and $0.4(1.9 \%) \mathrm{kg} / \mathrm{d}$ reduction in predicted DMI was detected during wk 1, 2, and 3 , respectively. Using bivariate analysis, d 3 AGP explained $10 \%$ of the variation in DMI during wk 1 . We

Received June 4, 2020.

Accepted August 8, 2020.

*Corresponding author: bjbrad@msu.edu explored the clinical utility of d 3 AGP to diagnose low DMI, defined as wk 1 DMI $>1$ standard deviation below the mean. Receiver operating characteristic analysis identified a threshold of $480.9 \mu \mathrm{g} / \mathrm{mL}$, providing $76 \%$ specificity and $48 \%$ sensitivity (area under the curve = 0.60). Limited associations occurred between AGP and blood biomarkers; however, AGP was associated with plasma haptoglobin concentration postpartum and incidence of displaced abomasum, retained placenta, and metritis. These results demonstrate a negative association between plasma AGP concentration and DMI in early-postpartum dairy cows, although its diagnostic performance was marginal. Further investigation into whether AGP directly suppresses DMI in dairy cattle is warranted.

Key words: biomarker, appetite, periparturient cow

\section{INTRODUCTION}

Dairy cows transitioning to lactation experience systemic inflammation, with chronic subacute inflammation appearing to lead to long-term production losses (Bradford et al., 2015). Inflammation is the biological mechanism whereby the body copes with pathogenic or nonpathogenic stimuli to resolve an issue and return to homeostasis. Cytokine and acute-phase protein production are hallmarks of inflammation, with cytokine production by immune cells markedly increasing after tissue insult, further leading to production of acute-phase proteins. These compounds, as indicators of inflammatory status, have consistently been linked to poor performance in dairy cows (Humblet et al., 2006; McCarthy et al., 2016), and extensive evaluation of acute-phase proteins as biomarkers of various diseases in ruminants has been performed (Ceciliani et al., 2012). Additionally, cytokines have been directly implicated in reducing feed intake through action on the hypothalamus (Wong and Pinkney, 2004), linking 
Table 1. Experiments and number of plasma samples analyzed $(n=2,086)$ on day relative to parturition

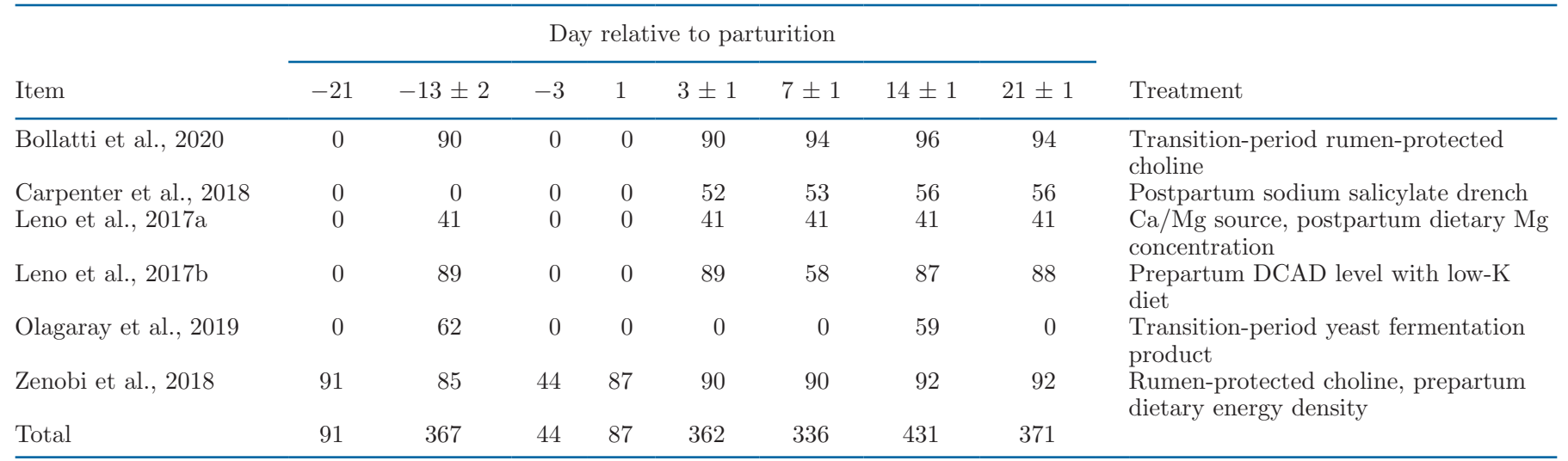

the immune response as an additional pathway for feed intake regulation beyond the traditional physical, endocrine, and metabolic homeostatic factors eloquently outlined by Allen and Piantoni (2013).

Orosomucoid, or $\alpha$-1-acid glycoprotein (AGP), is a positive acute-phase protein produced primarily in the liver (Hochepied et al., 2003). The role of AGP is not entirely clear, but it is a common lipocalin that also has immunomodulatory effects, working mostly in an anti-inflammatory manner (Fournier et al., 2000; Ceciliani and Lecchi, 2019). Two reports have demonstrated compelling evidence that AGP works directly to reduce feed intake in rats after intracerebroventricular infusion (Bellinger and Mendel, 1990), intraperitoneal injection, or peripheral administration (Sun et al., 2016). More mechanistically, AGP was found to bind the hypothalamic leptin receptor in mice, which in turn activates the downstream JAK2-STAT3 pathway to relay satiety signals (Sun et al., 2016). The hypothalamus is an important structure in the regulation of energy intake (Schwartz et al., 2000). However, very recent reports demonstrate a lack of effect of AGP on STAT3 signaling and feed intake in ruminants (Gregg et al., 2019; McGuckin et al., 2020).

Considering that plasma AGP concentration increases in postpartum dairy cows in a pattern similar to other acute-phase proteins (Cairoli et al., 2006; Jafari et al., 2006), and peripartum cows often exhibit depressed feed intake, we hypothesized that plasma AGP concentration is negatively related to DMI during the transition period. The objectives of this study were (1) to assess peripartum AGP concentration using a large sample size, (2) to determine the relationship between AGP and DMI in dairy cows during the transition period, (3) to assess the prognostic value of AGP relative to other biomarkers to predict cows at risk of low DMI, and (4) to access the prognostic value of AGP to predict postpartum disease.

\section{MATERIALS AND METHODS}

\section{Animals and Samples}

Blood plasma samples $(\mathrm{n}=2,086)$ from 434 Holstein cows were obtained from 6 previously conducted studies since 2014 at 3 institutions (Cornell University, University of Florida, and Kansas State University; Leno et al., 2017a,b; Carpenter et al., 2018; Zenobi et al., 2018; Olagaray et al., 2019; Bollatti et al., 2020). All samples were obtained $\pm 21 \mathrm{~d}$ relative to parturition, with specific sample days for each study outlined in Table 1. Individual daily feed intake data were available from all cows included in analysis. Detailed descriptions of study methodology, including analysis of other blood biomarkers, were previously published for each of these studies. Samples were analyzed in duplicate.

\section{Sample Analysis}

Initial attempts at quantifying AGP involved validating a previously reported ELISA procedure (Blees et al., 2017) modified to use a commercially available purified bovine AGP (product \# G3643, lot no. 111M7401V; Sigma-Aldrich, St. Louis, MO) dissolved in distilled, deionized water for the standard curve to avoid nonspecific binding. Lack of detectability of the purified bovine AGP prompted evaluation of commercial ELISA kits (MyBioSource Inc., San Diego, CA; ICL Inc., Portland, OR) to determine whether the commercially purified AGP could be detected, and to potentially validate the kits for large-scale AGP quantification. The purified bovine AGP was not detectable on either kit, necessitating the use of commercial kit standards.

Samples for the complete analysis were analyzed using a bovine-specific ELISA kit (catalog \#E-10AGP; ICL Inc.) according to manufacturer specifications at a dilution of 1:20,000. The kit uses a lyophilized puri- 
Table 2. Spike and recovery results of the bovine ELISA kit (ICL Inc., Portland, OR)

\begin{tabular}{lcccc}
\hline & \multicolumn{2}{c}{ AGP concentration ${ }^{1}(\mathrm{ng} / \mathrm{mL})$} & & \\
\cline { 2 - 3 } $\begin{array}{l}\text { Spike } \\
\text { (ng/mL) }\end{array}$ & Expected & Observed & Recovery $(\%)$ & SD $^{2}$ \\
\hline 5 & 26.3 & 29.0 & 110.3 & 2.1 \\
10 & 31.3 & 32.7 & 104.6 & 2.7 \\
20 & 41.3 & 38.3 & 92.9 & 0.7 \\
\hline${ }^{1} \mathrm{AGP}=\alpha$-1-acid glycoprotein. & & \\
${ }^{2}$ Standard deviation of the observed concentrations, performed in triplicate.
\end{tabular}

fied bovine AGP from serum as a standard curve. The 4-step dilution was performed via a robotic multichannel pipetting system (Integra Viaflo Assist, Integra Biosciences Corp., Hudson, NH), using the diluent buffer provided in the kit. Assay performance was assessed using spike and recovery and linearity of dilution techniques. Recovery of AGP was determined by spiking a known quantity of the standard into diluted sample (Table 2). A linearity of dilution experiment was conducted to test the behavior of the samples at various concentrations in the range of the standard curve by serially diluting plasma in the assay buffer (Table 3). According to the results compared with the linear portion of the standard curve, plasma samples were diluted 1:20,000 to achieve approximately $20 \mathrm{ng} / \mathrm{mL}$ final concentration. Two internal control samples were analyzed in duplicate on each plate, with intra-assay coefficient of variation $(\mathrm{CV})$ of 3.8 and $3.0 \%$ and interassay $\mathrm{CV}$ of 15.0 and $17.3 \%$, respectively, for each sample.

\section{Statistical Analysis}

Plasma AGP mean concentration on each sampling date was obtained by using repeated measures in the Mixed procedure of SAS (version 9.4, SAS Institute Inc., Cary, NC), with the model including the random effect of study. Data were $\log _{10}$ transformed to achieve normality and reverse transformed to obtain means. Bivariate linear regression, and subsequently linear and quadratic regression, was used to assess the relationship between AGP and DMI in subsequent weeks using JMP (version 13.0, SAS Institute Inc.). DMI was averaged over a 3 -d period following each blood sampling time point prepartum ( $\mathrm{d}-21,-12 \pm 3$, and -3 ), except for blood sample time point $\mathrm{d}-21$ for which DMI was averaged over d -15 to -13 . For postpartum data, DMI was averaged over a 1-wk period for each week postpartum. Days used to calculate DMI averages for each week relative to parturition are outlined in Table 4. For significant bivariate associations, the following linear and quadratic model was used to further analyze the association between plasma AGP concentration and DMI:

$$
\mathrm{Y}_{\mathrm{ij}}=\mu+\mathrm{A}+\mathrm{A} \times \mathrm{A}+\mathrm{T}_{\mathrm{i}}+\mathrm{e}_{\mathrm{ij}}
$$

where $\mu$ is the overall treatment mean, $\mathrm{A}$ is the linear effect of plasma AGP concentration, $\mathrm{A} \times \mathrm{A}$ is the quadratic effect of plasma AGP concentration, $T_{i}$ is the random effect of unique treatment within each study ( $\mathrm{i}=1$ to 19 ), and $\mathrm{e}_{\mathrm{ij}}$ is the residual error ( $\mathrm{j}=1$ to 30$)$. Analysis of the association between plasma AGP concentration and concentration of other blood biomarkers was conducted with the same model. Quadratic effects were removed from the model when $P>0.10$.

Residuals were analyzed for normality, and data were natural log-transformed when appropriate. Studentized residuals were evaluated, and outliers $>3.5$ or $<-3.5$ were excluded from analysis. Significance was declared at $P<0.05$, and tendencies when $P<0.10$.

Nominal logistic modeling was used to determine the association between plasma AGP concentration

Table 3. Linearity of dilution results for $\mathrm{AGP}^{1}$ using bovine ELISA kit (ICL Inc., Portland, OR)

\begin{tabular}{|c|c|c|c|c|}
\hline \multirow[b]{2}{*}{ Dilution rate } & \multicolumn{2}{|c|}{ AGP concentration $(\mathrm{ng} / \mathrm{mL})$} & \multirow[b]{2}{*}{$\%$ of expected } & \multirow[b]{2}{*}{$\mathrm{SD}^{2}$} \\
\hline & Observed & Expected & & \\
\hline $1: 5,000$ & 88.5 & - & - & 11.5 \\
\hline $1: 10,000$ & 36.4 & 44.2 & 82.2 & 0.1 \\
\hline $1: 20,000$ & 20.9 & 18.2 & 115.2 & 1.2 \\
\hline $1: 40,000$ & 10.7 & 10.5 & 102.5 & 0.7 \\
\hline $1: 80,000$ & 5.1 & 5.4 & 95.4 & 0.4 \\
\hline
\end{tabular}


Table 4. Association between plasma AGP concentration ${ }^{1}$ (natural $\log \mu \mathrm{g} / \mathrm{mL}$ ) and DMI $(\mathrm{kg} / \mathrm{d}$ ); significant linear associations were subsequently analyzed with quadratic and linear regression, including random effect of treatment(study) in the model

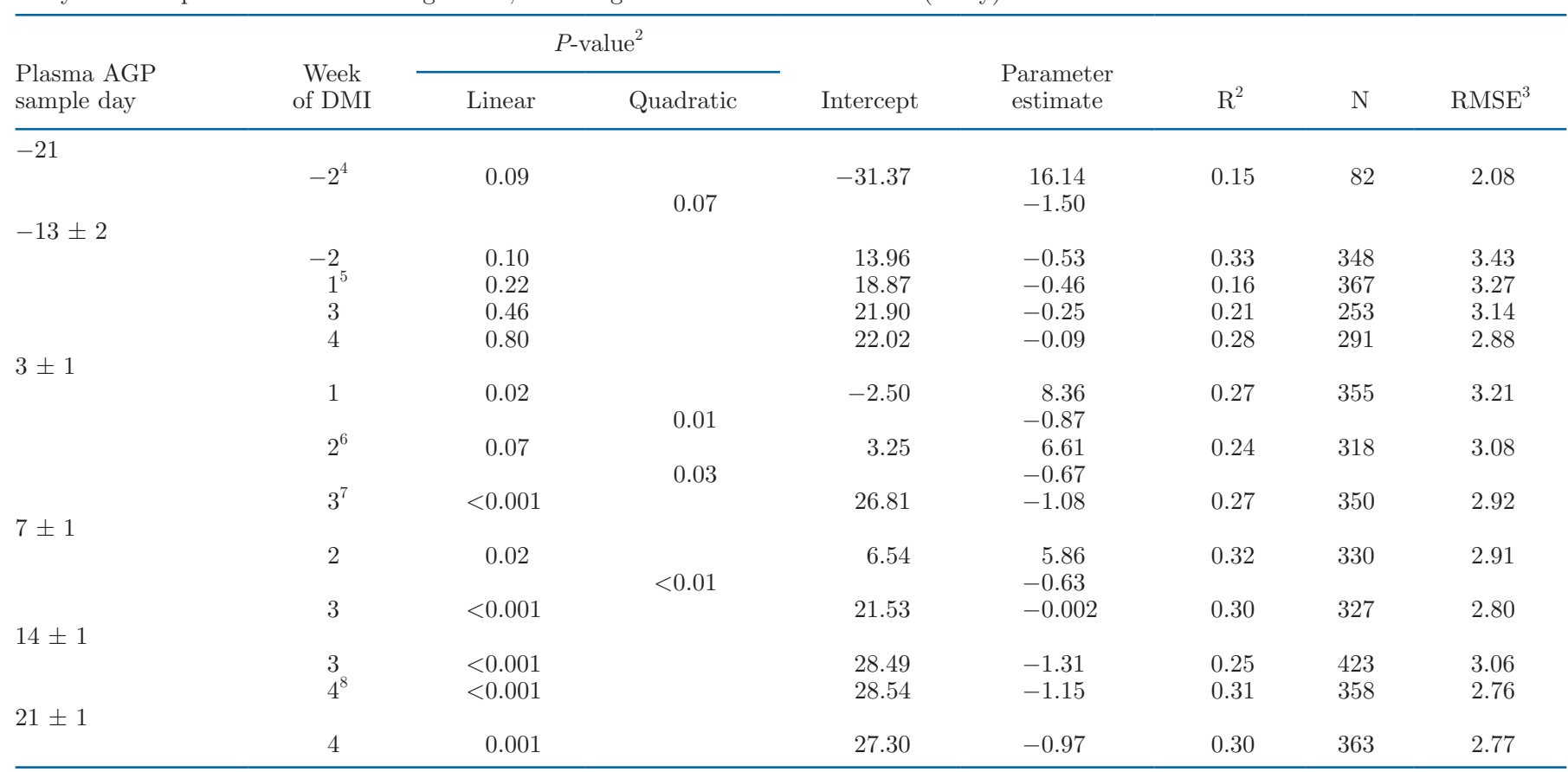

${ }^{1} \mathrm{AGP}=\alpha$-1-acid glycoprotein

${ }^{2}$ All data were transformed using natural log to achieve normality and data are presented in the transformed state.

${ }^{3} \mathrm{RMSE}=$ root mean squared error

${ }^{4} \mathrm{DMI}$ averaged over $3 \mathrm{~d}$ following plasma sample date $(\mathrm{d}-13 \pm 2)$.

${ }^{5} \mathrm{DMI}$ averaged over $\mathrm{d} 1$ to 7 .

${ }^{6} \mathrm{DMI}$ averaged over d 8 to 14 .

${ }^{7}$ DMI averaged over d 15 to 21 .

${ }^{8}$ DMI averaged over d 22 to 28 .

on a given day and incidence of postpartum disease using the fixed effect of AGP and the random effect of study. From this information, we used receiver operating characteristic (ROC) analysis using JMP to assess the ability of AGP to predict disease incidence for diseases presenting sufficient sample size (sensitivity and specificity $=0.70 ;$ marginal error $=0.20 ; \alpha=0.05$; Hajian-Tilaki, 2014; Bujang and Adnan, 2016), based upon previously reported rates of disease and culling (Smith et al., 2000; McLaren et al., 2006; Berge and Vertenten, 2014).

We also carried out ROC analysis to determine the utility of d 3 AGP for detecting cows with low feed intake. Day 3 AGP concentration was used because the association between AGP and DMI was most significant early in the postpartum period. Low feed intake was defined as 1 standard deviation (SD) less than the mean wk 1 DMI. For all ROC analyses we determined the threshold AGP concentration offering the optimal balance between sensitivity and specificity, determined based on the concentration offering the greatest sum of calculated sensitivity + specificity.
A proportional hazards regression model was constructed using the fixed effects of AGP and study to determine the association of AGP concentration with risk of culling by 280 DIM. Furthermore, the concentration of AGP was classified as being above or below the threshold determined from ROC analysis to construct survival curves assessing the association of peripartum AGP with culling by 280 DIM. The cutoff of $280 \mathrm{~d}$ was chosen because, for 2 of the studies (Zenobi et al., 2018; Bollatti et al., 2020), representing half of the data, information was available only up to 280 DIM, limiting the ability to evaluate the full lactation on all animals.

\section{RESULTS}

Prepartum AGP concentrations were relatively stable for d $-21(248 \pm 35.0 \mu \mathrm{g} / \mathrm{mL}), \mathrm{d}-13(223 \pm$ $30.2 \mu \mathrm{g} / \mathrm{mL}), \mathrm{d}-3(212 \pm 30.2 \mu \mathrm{g} / \mathrm{mL})$, and $\mathrm{d} 1(273$ $\pm 37.4 \mu \mathrm{g} / \mathrm{mL}$; Figure 1). Plasma AGP concentration increased beginning on d $3(377 \pm 51.0 \mu \mathrm{g} / \mathrm{mL})$ before numerically increasing to a peak on d $14(445 \pm 59.0$ $\mu \mathrm{g} / \mathrm{mL})$ and declining numerically to d $21(387 \pm 52.2$ 
$\mu \mathrm{g} / \mathrm{mL}$ ). Plasma concentrations of AGP on $\mathrm{d} 3$ to $\mathrm{d}$ 21 were significantly greater than AGP on any day from $\mathrm{d}-21$ to $\mathrm{d} 1(P<0.001)$. Results for associations between AGP and DMI are presented in Table 4. All associations between the variables were negative over the range of observed values (accounting for the quadratic nature of some relationships). Concentration of AGP on $d-21$ was negatively related in a quadratic manner with DMI of wk $-2(P=0.07)$. On d 3 , AGP was negatively associated with DMI on wk 1 and wk 2 in a quadratic fashion $(P=0.01 ; P=0.03)$ and was negatively associated in a linear manner with wk 3 DMI $(P<0.001)$. The AGP concentration on $\mathrm{d} 7 \mathrm{had}$ a negative quadratic association with wk 2 DMI $(P<$ $0.01)$ and was negatively associated with wk 3 DMI $(P$ $<0.001$ ). Day 14 AGP concentration was negatively associated with DMI in a linear manner for both wk 3 and wk $4(P<0.001)$. The AGP concentration on $\mathrm{d}$ 21 was negatively associated with DMI in wk $4(P=$ $0.001)$.

Using the intercepts and parameter estimates shown in Table 4, predicted DMI changes over the interquartile range of d 3 AGP were calculated. As d 3 AGP concentration increased over the interquartile range, a calculated $1.4(8.5 \%), 0.5(2.7 \%)$, and $0.4(1.9 \%) \mathrm{kg} / \mathrm{d}$ reduction in predicted DMI was detectable during wk

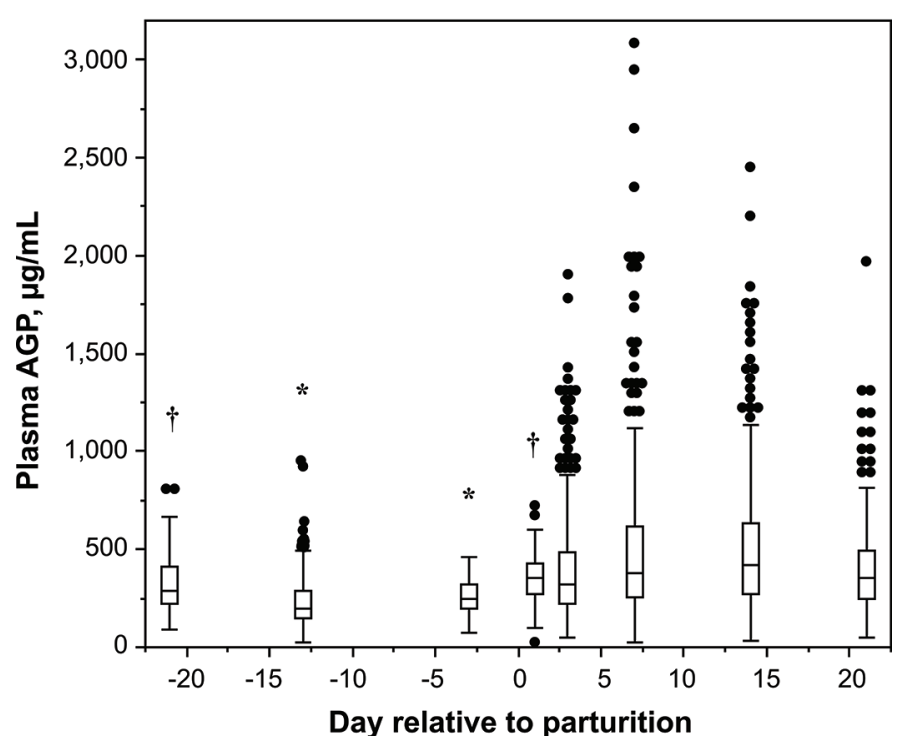

Figure 1. Box and whisker plots and outliers of plasma $\alpha$-1-acid glycoprotein (AGP) concentration of peripartum dairy cows. Refer to Table 1 for number of samples analyzed at each time point. Data were transformed using $\log _{10}$ to achieve normality, and reverse-transformed data are shown. Symbols above each day indicate difference from postpartum time points $(*=$ different from d-1 to d-21 time points, $P<$ $0.001 ; \dagger=$ different from d-3 to d-21 time points, $P<0.001$ ). The box indicates the 25th percentile, median, and 75 th percentile, and whiskers represent data within 1.5 times the interquartile range. Black dots are outliers.
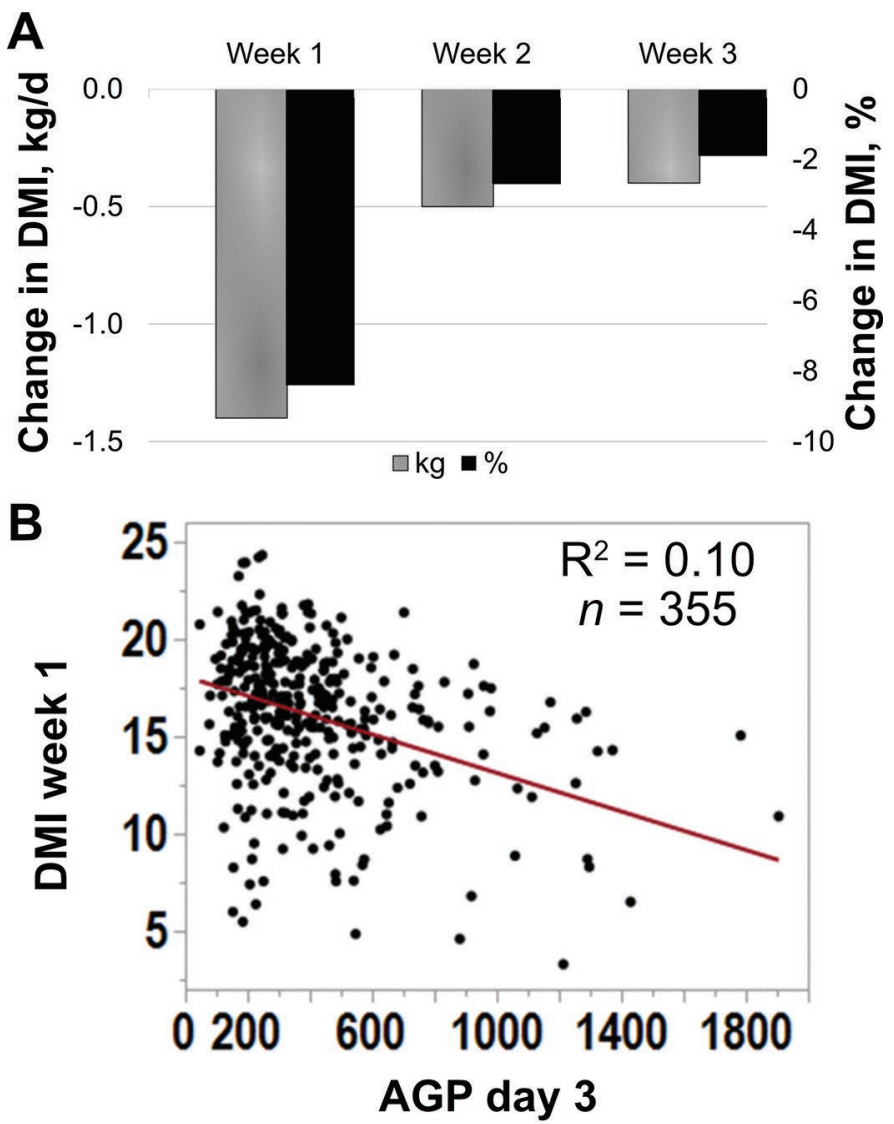

Figure 2. Plasma $\alpha$-1-acid glycoprotein (AGP) concentration on d 3 postpartum is negatively associated with early-lactation DMI. The reduction in DMI calculated over the interquartile range of $\mathrm{d} 3$ plasma AGP concentration (222 to $488 \mu \mathrm{g} / \mathrm{mL}$; panel A) and the bivariate fit of d 3 AGP $(\mu \mathrm{g} / \mathrm{mL})$ and wk 1 DMI (panel B).

1, 2, and 3, respectively (Figure 2A). Using bivariate analysis, d 3 AGP explained $10.0 \%$ of the variation in DMI during wk 1 (Figure 2B). Receiver operating characteristic analysis identified a threshold of 480.9 $\mu \mathrm{g} / \mathrm{mL}$, providing $76 \%$ specificity and $48 \%$ sensitivity [Figure 3; area under the curve $(\mathbf{A U C})=0.60]$ in detecting low feed intake.

Results for associations between AGP and other blood plasma biomarkers can be found in Supplemental Tables S1 to S8 (https://doi.org/10.3168/jds.2020 -19025). Plasma AGP concentration on d 1 tended to be positively associated with plasma glucose concentration on $\mathrm{d} 7(P=0.06)$ and $\mathrm{d} 14(P=0.07)$. On $\mathrm{d}-3$, plasma AGP was positively associated with d 21 free fatty acids $(P=0.04)$ and tended to be positively associated with d 14 free fatty acids $(P=0.08)$, whereas d 7 AGP tended to be negatively associated with $\mathrm{d} 14$ free fatty acids $(P=0.07)$. Plasma AGP on $\mathrm{d}-13$ was negatively associated with insulin concentration at the same time point $(P=0.04)$. The strongest associations 


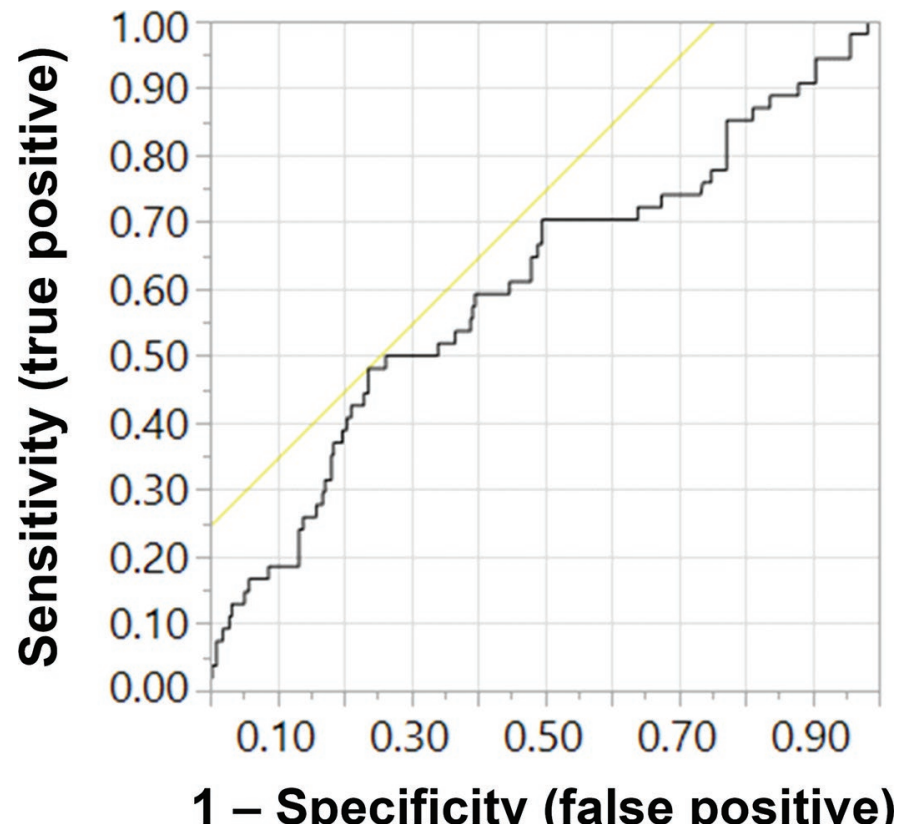

Figure 3. Receiver operating characteristics curve (jagged line) that shows the critical threshold (intersection with solid line) for plasma $\alpha$-1-acid glycoprotein (AGP) concentration on d $3(480.9 \mu \mathrm{g} / \mathrm{mL})$, predicting low DMI for wk 1 (area under the curve $=0.60$ ). The critical threshold AGP concentration offered the optimal balance between sensitivity and specificity, determined based on greatest sum of calculated sensitivity and specificity. Low DMI was defined as wk 1 DMI less than $1 \mathrm{SD}$ below the mean $(<12.5 \mathrm{~kg} / \mathrm{d} ; \mathrm{n}=54)$.

were between AGP and BHB and haptoglobin. On d -13 , AGP was negatively associated with $\operatorname{BHB}(P=$ 0.02), whereas d 7 AGP concentration was positively associated with BHB on d $7(P<0.01$; Table 5$)$. The concentrations of AGP and haptoglobin were positively associated on $\mathrm{d} 3,7$, and $14(P \leq 0.03$; Table 5$)$, and d 7 AGP was also associated with d 14 haptoglobin $(P$ $<0.01$; Table 5).

Strong associations were detectable between postpartum AGP concentration and transition cow diseases.
The concentration of AGP on d 3 to $14(P<0.001)$ and d $21(P=0.02$; Table 6$)$ was positively associated with postpartum incidence of retained placenta. In a similar fashion, AGP on d 3 to $21(P<0.001$; Table 6$)$ was positively associated with incidence of metritis. On $\mathrm{d} 7$ $(P=0.03), 14(P=0.04)$, and $21(P<0.001$; Table 6$)$, AGP was positively associated with hyperketonemia. On d 21, AGP was positively associated with mastitis $(P=0.03)$. Furthermore, AGP was positively associated on d $1(P=0.04)$ with culling by 280 DIM. Overall, $19 \%$ of at-risk cows left the herd by 280 DIM, and proportional hazard analysis revealed that increased AGP concentration over the interquartile range (432 vs. 271 $\mu \mathrm{g} / \mathrm{mL})$ on $\mathrm{d} 1$ was associated $(P=0.02)$ with a $15 \%$ decreased risk of culling through 280 DIM (0.85 hazard ratio, $95 \%$ CI: 0.82 to 0.95 ). Survival curves were constructed for cohorts using the optimal threshold for $\mathrm{d} 1$ AGP concentration $(351 \mu \mathrm{g} / \mathrm{mL})$ determined via ROC analysis, but no evidence of difference was detectable between cows above and below the threshold $(P=0.11$ Wilcoxon test; data not shown).

\section{DISCUSSION}

To accomplish most of our objectives for this study, we first had to identify an accurate, high-throughput method for determination of AGP concentration in bovine plasma. To date, most of the quantification of circulating AGP has been conducted via radial immunodiffusion assays (Jafari et al., 2006; Eckersall et al., 2007), immunoturbidimetric assay (Bence et al., 2005; Mooney et al., 2006), or gel electrophoresis methods (Ling et al., 1996; Cairoli et al., 2006), or by precipitating the protein and measuring absorbance (Lewis et al., 1989), none of which are suitable for analyzing large quantities of samples. More recent efforts have resulted in development of ELISA procedures to quantify AGP (Agra et al., 2017; Caperna et al., 2017), with only 1

Table 5. Association between plasma $\alpha$-1-acid glycoprotein (AGP) concentration (natural $\log \mu \mathrm{g} / \mathrm{mL}$ ) and plasma BHB ( $\mu M$ ) and haptoglobin $(\mathrm{Hp})$ concentrations ${ }^{1}$ for select sampling points postpartum

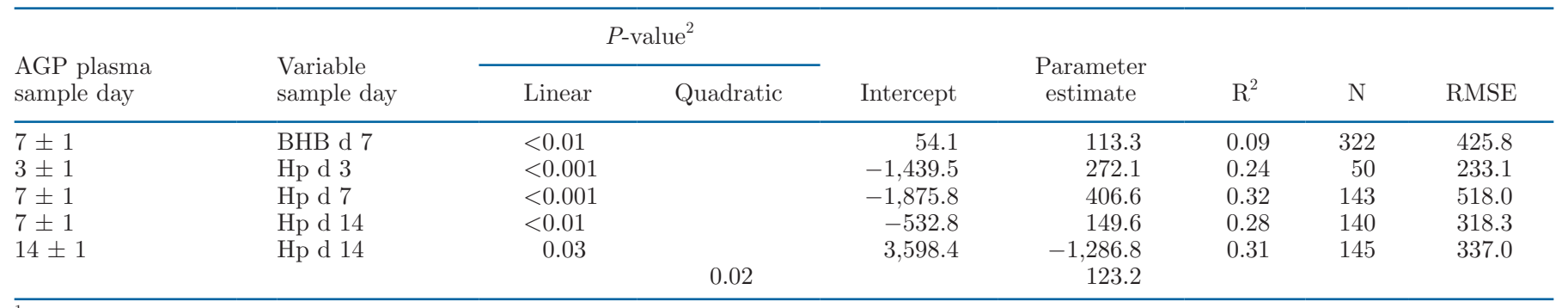

${ }^{1}$ Data for haptoglobin from Carpenter et al. (2018) were reported as $\mu \mathrm{g} / \mathrm{mL}$, and data from Bollatti et al. (2020) and Zenobi et al. (2018) were reported as optical density. Differences between concentration reporting methods are accounted for with the random effect of treatment (study) in our model.

${ }^{2}$ All data for AGP concentration were transformed using natural log to achieve normality, and data are presented in the transformed state. 
study quantifying bovine plasma AGP (McGuckin et al., 2020). For this reason, we tested several ELISA kits and found the one used in this study to be acceptable for linearity and recovery, and it most closely aligned with previously reported bovine plasma AGP concentrations using other techniques (Horadagoda et al., 1999; Jafari et al., 2006; Ceciliani et al., 2012).

\section{Changes in Peripartum AGP Concentration}

Our first objective was to assess AGP concentrations on a large sample size of peripartum dairy cows. The pattern of plasma AGP concentration shifts during the transition period in this study is similar to those reported for other positive acute-phase proteins, such as haptoglobin, LPS binding protein, and serum amyloid A (Jafari et al., 2006; Abuajamieh et al., 2016; McCarthy et al., 2016). The concentration of AGP significantly increases postpartum by $\mathrm{d} 3$, reaching an apparent peak at 14 DIM before numerically trending toward prepartum concentrations. This is similar to the pattern shown by McGuckin et al. (2020), where postpartum concentrations of AGP were significantly greater than prepartum concentrations, but lacked evidence of differences across time points in the first 3 wk postpartum. In another study, plasma AGP peaked

Table 6. Association between $\alpha$-1-acid glycoprotein (AGP; natural $\log \mu \mathrm{g} / \mathrm{mL}$ ) and incidence of postpartum disease and culling in transition dairy cows; all associations were positive unless otherwise denoted by a superscript

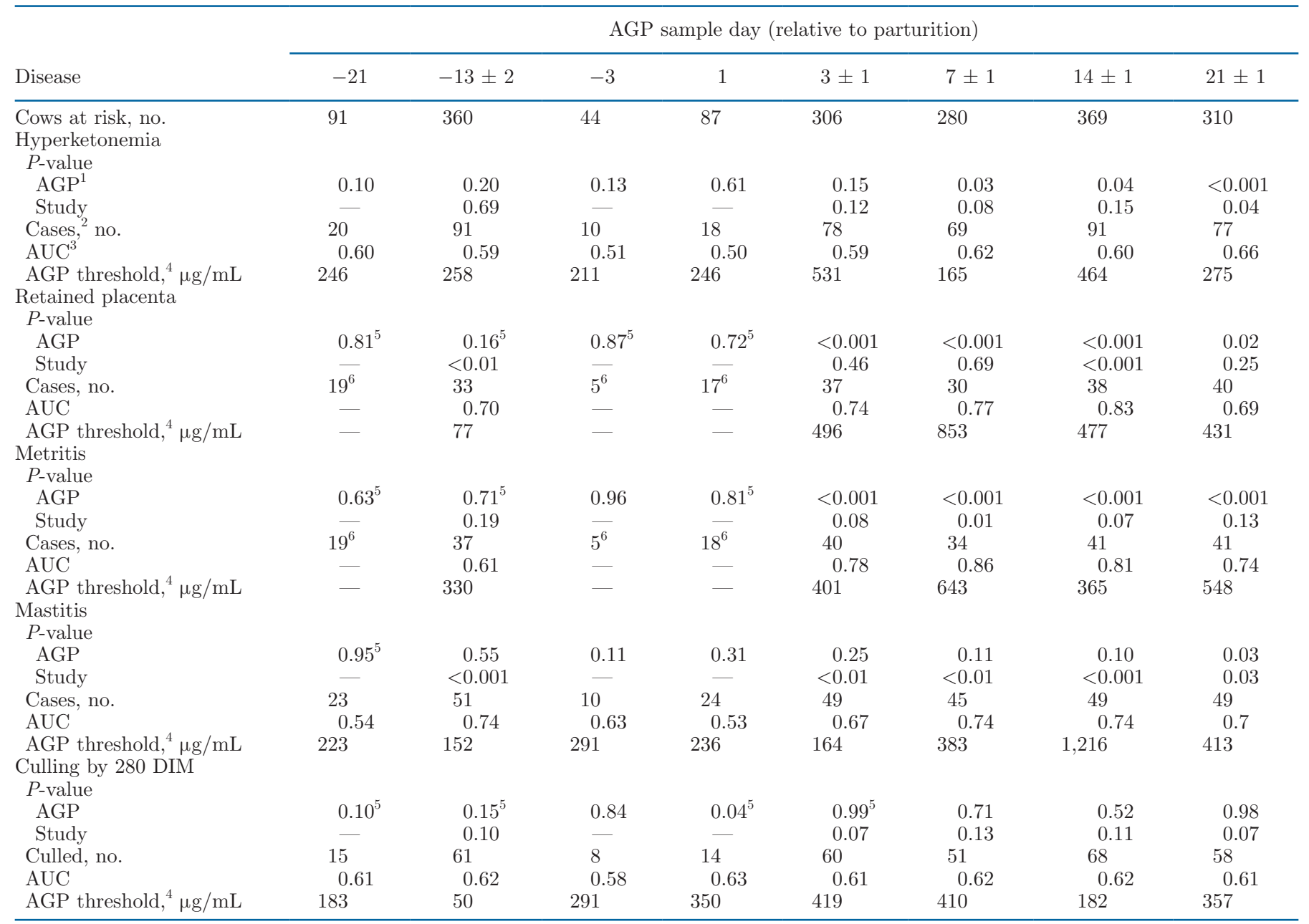

${ }^{1}$ Data for AGP concentration were transformed using natural log to achieve normality, and data are presented in the transformed state.

${ }^{2}$ Number of observations of animals in the data set for a particular sampling day that were diseased at some point during the study period. Data were not available for onset of disease.

${ }^{3}$ Receiver operating characteristic (ROC) area under the curve (AUC) for AGP predicting postpartum disease.

${ }^{4}$ Concentration offering the maximum difference between sensitivity and (1 - specificity).

${ }^{5}$ Negative association between plasma AGP and disease or culling.

${ }^{6}$ Insufficient sample size for diagnostic testing using ROC analysis (Hajian-Tilaki, 2014). 
at 7 DIM and gradually declined to near prepartum concentrations by 21 DIM (Jafari et al., 2006). Bovine plasma AGP concentration is correlated with AGP mRNA abundance in the liver during the transition period, with an upregulation of hepatic $A G P$ mRNA postpartum (McGuckin et al., 2020). Compared with plasma haptoglobin concentrations, AGP declines at a much slower rate postpartum (Sheldon et al., 2001; Jafari et al., 2006). In a study conducted by Horadagoda et al. (1999), cattle with chronic or acute inflammation were found to have serum AGP concentrations of 815 and $1,101 \mu \mathrm{g} / \mathrm{mL}$, respectively, with a normal reference range of 200 to $450 \mu \mathrm{g} / \mathrm{mL}$. Based upon the plasma AGP concentrations in the present study, most postpartum cows experienced elevated inflammatory tone but perhaps not chronic inflammation. However, great variation in AGP concentration occurs postpartum, so it is possible that a sizable minority of cows were experiencing chronic or even acute inflammation. We must also consider that the reference values in the study by Horadagoda et al. (1999) were determined by a single radial immunodiffusion assay, compared with an ELISA in our study, so direct comparisons are tenuous.

\section{Associations Between AGP and DMI}

One of the primary objectives of this study was to assess the relationship between AGP concentration and DMI. The negative associations between plasma AGP concentration and DMI were most significant postpartum, and AGP concentration on any given postpartum sampling day was negatively associated with DMI in subsequent weeks. This is consistent with previous work associating postpartum inflammatory markers with subsequent performance reduction in dairy cows (Huzzey et al., 2015; McCarthy et al., 2016). In pigs, serum AGP concentration is negatively correlated with daily feed intake and weight gain at 18 and 24 wk of age (Clapperton et al., 2005), and activation of the immune system causing an increase in AGP tended to decrease daily feed intake in another study (Williams et al., 1997a,b). In fact, others have suggested that AGP may serve as an independent predictor of production performance impairment in livestock (Caperna et al., 2013).

Administration of exogenous human AGP reduces voluntary feed intake in rodents by acting on the hypothalamic leptin receptor and activating the JAK2/ STAT3 pathway (Bellinger and Mendel, 1990; Sun et al., 2016), although very recent in vitro evidence suggests that bovine and human AGP do not elicit STAT3 signaling in cells expressing bovine leptin receptors (McGuckin et al., 2020). Another recent study administered purified bovine AGP both peripherally and centrally in sheep, with no effect on feeding rate or cumulative intake (Gregg et al., 2019). It is unclear why human AGP activates the leptin receptor in mice but bovine and human AGP do not activate the bovine leptin receptor. It is certainly possible that species-specific differences in AGP modes of action exist. Further, plasma leptin concentration declines by $\sim 50 \%$ in the transition to lactation and remains low postpartum (Liefers et al., 2003; Janovick et al., 2011) as energy balance is declining in dairy cows at the same time. Ruminant feed intake during periods of negative energy balance is generally refractory to leptin (Henry et al., 2001; Morrison et al., 2001; Ehrhardt et al., 2016); the same "leptin resistance" phenomenon may prevent AGP from having effects on downstream leptin receptor signaling in transition dairy cows.

Although we cannot determine the cause-and-effect relationships of AGP with DMI in the present study, it is intriguing that a negative association exists postpartum. Postpartum dairy cows experience elevated inflammation, and many factors are involved in an inflammatory response, including the release of cytokines, which have been implicated in modulating feed intake through hypothalamic action (Wong and Pinkney, 2004). To our knowledge, no other acute-phase proteins have been directly implicated in central control of feed intake, so it could be that a variety of molecules related to inflammation work centrally to affect intake during an inflammatory response.

To further evaluate the negative association between AGP and DMI, we calculated the predicted change in DMI for the d 3 AGP interquartile range (25th to 75 th percentile) using parameter estimates from the best-fit equation for wk 1 DMI (Table 4). As d 3 AGP increased over the interquartile range, average daily DMI during wk 1 was calculated to decrease $8.5 \%$, or $1.4 \mathrm{~kg}$ (Figure 2 ). For comparison, the reductions in DMI for retained placenta, metritis, and milk fever were estimated to be $0.8,5.1$, and $14.7 \mathrm{~kg} / \mathrm{d}$, respectively (Bareille et al., 2003). Although the reduction of DMI over the AGP interquartile range does not initially appear substantial compared with diseases that plague modern dairy operations, it is still concerning and warrants further investigation. Furthermore, weak forward associations suggest that AGP may serve as a leading indicator of suboptimal DMI, rather than a trailing indicator such as clinical disease diagnosis. For example, d 3 AGP was negatively associated with DMI beyond wk 1 (Table 4), and AGP on d 7 and 14 was negatively associated with DMI for multiple weeks. One limitation of these data is the relatively high interplate variability (CV of $17.3 \%$ ) for AGP quantification, which may in part explain the modest associations between AGP and DMI. A more precise measurement of AGP might have better explained variation in DMI postpartum. 


\section{Prognostic Ability of AGP to Predict Poor DMI}

The fact that AGP may serve as a leading indicator of suboptimal postpartum DMI led us to our third objective, which was to assess the prognostic value of AGP to predict cows at risk of low DMI using ROC analysis. The ROC analysis is a method for evaluation of the accuracy of a clinical diagnostic test, where the optimum combination of sensitivity (true positive) and specificity (lack of false positive) of the test are maximized in ideal situations (Gardner and Greiner, 2006). As a continuous variable, DMI presents challenges for ROC analysis due to the difficulty in selecting a useful cutoff point (Gardner and Greiner, 2006). For determination of low DMI in this study, considering that there has been no proposed threshold of acute DMI depression in transition cows, we used the arbitrary definition of wk 1 DMI that is 1 SD below the mean. In the current study, the AUC of 0.6 (Figure 3) does not create confidence in the ability of AGP to predict acute depressed DMI. Constraining the definition of low DMI to 2 SD below the mean did not improve diagnostic performance (AUC $=0.55$; data not shown). Therefore, although AGP is clearly negatively associated with DMI postpartum, it is a poor predictor of acute DMI depression.

\section{Relationship Between AGP and Common Biomarkers}

Should AGP be a useful indicator of future DMI depression, it would ideally be independent of other blood biomarkers that are cheaply and easily measured today, such as glucose or BHB. Out of 107 measured associations in this study between AGP and other blood biomarkers throughout the peripartum period (Supplemental Tables S1 to S8, https://doi.org/10 .3168/jds.2020-19025), only 8 were significant. Considering the number of analyses for these comparisons, the 8 significant results may be a function of type I error at the $95 \%$ confidence rate. The finding that AGP is poorly associated with other biomarkers at many time points suggests that it could serve as an independent biomarker for predicting postpartum health or performance.

Despite minimal associations between AGP and plasma biomarkers, we detected several associations that may be biologically meaningful. The positive association between AGP and BHB on d 7 (Table 5) occurs at a time when both factors are normally increasing due to calving and the induction of negative energy balance. Others have demonstrated an association between acute-phase proteins and ketosis in postpartum cows (Abuajamieh et al., 2016), and more controlled studies have administered inflammatory components, such as tumor necrosis factor- $\alpha$, and increased liver fat concentration (Bradford et al., 2009), BHB (Trevisi et al., 2009), and incidence of ketosis (Yuan et al., 2013). In this light, the limited associations between AGP and BHB concentrations postpartum are biologically plausible.

Not surprisingly, plasma AGP concentration was positively associated with plasma haptoglobin concentration on d 3, d 7, and d 14 (Table 5). Postpartum AGP and haptoglobin have been shown in other studies to follow a similar pattern postpartum with a spike on d 7 before declining (Jafari et al., 2006), but the haptoglobin concentration declines to stable concentrations about 1 wk earlier than does AGP (Sheldon et al., 2001). This may explain the lack of persistent future associations between AGP and haptoglobin in this study despite the strong associations on the same day, and may reflect the anti-inflammatory properties of AGP and its function to resolve inflammation (Ceciliani and Lecchi, 2019). Conversely, AGP and haptoglobin have an extremely weak correlation in healthy pigs (Clapperton et al., 2007). Others have shown a tendency for a relationship between prepartum haptoglobin and postpartum disease incidence (Huzzey et al., 2011), and peripartum haptoglobin is negatively associated with milk production (Huzzey et al., 2015).

\section{Relationship and Prognostic Ability of AGP for Disease and Culling}

Our final objective was to assess the prognostic value of AGP to predict postpartum disease. In this study, postpartum AGP concentration was positively associated with incidence of retained placenta and metritis, but for variables with sufficient sample size the diagnostic ability was marginal based upon the ROC AUC (Table 6). These diseases are common for postpartum dairy cows (Dubuc and Denis-Robichaud, 2017). Despite this strong positive association between AGP and postpartum disease, it is unlikely that AGP is a predictor of disease, but, rather, AGP may be increasing with other positive acute-phase proteins in response to the disease insult (Horadagoda et al., 1999; Sheldon et al., 2001). In normal uterine defense systems postpartum, bacterial invasion causes immune cell infiltration and inflammation, which can persist with the pathogenesis of endometritis and metritis (Esposito et al., 2014). Unfortunately, lack of data prevented us from further analyzing onset of disease and its relationship with AGP concentration in transition cows. Incidence of disease for the data set is outlined in Table 7 .

We were surprised to observe that AGP on d 1 was associated with reduced culling through 280 DIM. Although inflammation can be associated with negative production outcomes in chronic instances, it may be 
Table 7. Total incidence of postpartum disease and survival to 280 DIM by study in transition dairy cows

\begin{tabular}{lcc}
\hline & \multicolumn{2}{c}{$\mathrm{n}$} \\
\cline { 2 - 3 } Item & Total cases & Total animals $^{1}$ \\
\hline Hyperketonemia & 94 & 377 \\
Retained placenta & 41 & 377 \\
Metritis $^{2,3}$ & 41 & 318 \\
Mastitis & 52 & 377 \\
Culled by 280 DIM & 69 & 371
\end{tabular}

${ }^{1}$ No disease incidence data were available from Carpenter et al. (2018). ${ }^{2}$ Data on metritis incidence were not available from Olagaray et al. (2019).

${ }^{3}$ Defined as fetid, watery discharge. Complete descriptions can be found in the respective publications (Leno et al., 2017a,b; Zenobi et al., 2018; Bollatti et al., 2020).

required as a part of the natural adaptive mechanisms for a successful transition to lactation (Bradford et al., 2015). Transgenic overexpression of AGP increased survivability from lethal Klebsiella pneumonia infection in mice, and administration of AGP in normal animals before infection also had dramatic nonspecific protective effects (Hochepied et al., 2000). Similarly, administration of AGP before a lethal dose of tumor necrosis factor- $\alpha$ prevented death (Libert et al., 1994). The cows in this study were generally not exposed to lethal quantities of harmful pathogens or cytokine storms, and their survivability to $280 \mathrm{~d}$ is much longer than those found in mouse studies. However, we could hypothesize that the elevated AGP concentrations as a result of the natural increase in inflammation postpartum had some protective effects upon subsequent pathogen exposure, considering postpartum cows have elevated susceptibility to infection. Nonetheless, despite this negative association, the diagnostic ability of d 1 AGP to predict culling, as determined by ROC analysis, was poor $(\mathrm{AUC}=0.63$; Table 6$)$.

\section{CONCLUSIONS}

Plasma AGP concentration significantly increases by d 3 postpartum, with an apparent peak at 14 DIM. We found that AGP was negatively correlated with DMI postpartum, and DMI decreased approximately 8.5\% as plasma AGP increased over the interquartile range. It is possible that AGP could be used as a measure of inflammatory status in transition dairy cows, and an ELISA can serve as a reliable and repeatable method of quantification. We found that AGP was not related to many other blood biomarkers except for haptoglobin, demonstrating independence from other common biomarkers commonly used today. Although we detected a strong association between AGP and transition diseases, the disease may be causing the increase in AGP instead of AGP predicting disease. However, based upon ROC analysis, the diagnostic ability of AGP to predict suboptimal DMI is poor. Further work should focus on in vivo AGP administration to determine effects on feeding behavior, and work to determine potential mechanisms of AGP action on the hypothalamus in ruminant models should be conducted.

\section{ACKNOWLEDGMENTS}

This work was carried out with support from the Animal Nutrition, Growth, and Lactation program (grant no. 017-67015-26491) and Hatch Project 1018048 from the USDA National Institute of Food and Agriculture (Washington, DC). The authors thank Chadron Koehn and Gary Davis (Kansas State University, Manhattan) for many hours spent performing countless ELISA experiments. Their attention to detail and accuracy is greatly appreciated. The authors have not stated any conflicts of interest.

\section{REFERENCES}

Abuajamieh, M., S. K. Kvidera, M. V. S. Fernandez, A. Nayeri, N. C. Upah, E. A. Nolan, S. M. Lei, J. M. DeFrain, H. B. Green, K. M. Schoenberg, W. E. Trout, and L. H. Baumgard. 2016. Inflammatory biomarkers are associated with ketosis in periparturient Holstein cows. Res. Vet. Sci. 109:81-85. https://doi.org/10.1016/ j.rvsc.2016.09.015.

Agra, R. M., A. Varela-Román, R. González-Ferreiro, J. E. Viñuela, A. Castro-Pais, Á. Fernández-Trasancos, E. Díaz-Rodríguez, E. Álvarez, M. C. Carreira, F. F. Casanueva, J. R. González-Juanatey, and S. Eiras. 2017. Orosomucoid as prognosis factor associated with inflammation in acute or nutritional status in chronic heart failure. Int. J. Cardiol. 228:488-494. https://doi.org/10.1016/j .ijcard.2016.11.134.

Allen, M. S., and P. Piantoni. 2013. Metabolic control of feed intake. Vet. Clin. North Am. Food Anim. Pract. 29:279-297. https://doi .org/10.1016/j.cvfa.2013.04.001.

Bareille, N., F. Beaudeau, S. Billon, A. Robert, and P. Faverdin. 2003. Effects of health disorders on feed intake and milk production in dairy cows. Livest. Prod. Sci. 83:53-62. https://doi.org/10.1016/ S0301-6226(03)00040-X.

Bellinger, L. L., and V. E. Mendel. 1990. The effects of semi-and HPLC-Purified human satietin and $\alpha$-1-glycoprotein on ingestion and body weight. Brain Res. Bull. 25:941-947. https://doi.org/10 .1016/0361-9230(90)90192-3.

Bence, L. M., D. D. Addie, and P. D. Eckersall. 2005. An immunoturbidimetric assay for rapid quantitative measurement of feline $\alpha-1$ acid glycoprotein in serum and peritoneal fluid. Vet. Clin. Pathol. 34:335-341. https://doi.org/10.1111/j.1939-165X.2005.tb00058.x.

Berge, A. C., and G. Vertenten. 2014. A field study to determine the prevalence, dairy herd management systems, and fresh cow clinical conditions associated with ketosis in western European dairy herds. J. Dairy Sci. 97:2145-2154. https://doi.org/10.3168/jds .2013-7163.

Blees, T., C. Catozzi, C. Urh, S. Danicke, S. Haussler, H. Sauerwein, and F. Ceciliani. 2017. Development of an ELISA for the acutephase protein $\alpha$-1-acid glycoprotein (AGP) in cattle. Page 122 in Book of Abstracts of the 68th Annual Meeting of the European Federation of Animal Science, Tallinn, Estonia. European Federation of Animal Science, Rome, Italy.

Bollatti, J. M., M. G. Zenobi, N. A. Artusso, A. M. Lopez, C. D. Nelson, B. A. Barton, C. R. Staples, and J. E. P. Santos. 2020. Effects 
of rumen-protected choline on the inflammatory and metabolic status and health of dairy cows during the transition period. J. Dairy Sci. 103:4192-4205. https://doi.org/10.3168/jds.2019-17294.

Bradford, B. J., K. Yuan, J. K. Farney, L. K. Mamedova, and A. J. Carpenter. 2015. Invited review: Inflammation during the transition to lactation: New adventures with an old flame. J. Dairy Sci. 98:6631-6650. https://doi.org/10.3168/jds.2015-9683.

Bradford, B. J., L. K. Mamedova, J. E. Minton, J. S. Drouillard, and B. J. Johnson. 2009. Daily injection of tumor necrosis factor- $\alpha$ increases hepatic triglycerides and alters transcript abundance of metabolic genes in lactating dairy cattle. J. Nutr. 139:1451-1456. https://doi.org/10.3945/jn.109.108233.

Bujang, M. A., and T. H. Adnan. 2016. Requirements for minimum sample size for sensitivity and specificity analysis. J. Clin. Diagn. Res. 10:YE01-YE06. https://doi.org/10.7860/JCDR/2016/18129 .8744 .

Cairoli, F., M. Battocchio, M. C. Veronesi, D. Brambilla, F. Conserva, I. Eberini, R. Wait, and E. Gianazza. 2006. Serum protein pattern during cow pregnancy: Acute-phase proteins increase in the peripartum period. Electrophoresis 27:1617-1625. https://doi.org/ 10.1002/elps.200500742.

Caperna, T. J., A. E. Shannon, L. A. Blomberg, M. Stoll, and T. G. Ramsay. 2013. Identification of $\alpha-1$ acid glycoprotein (AGP) as a potential marker of impaired growth in the newborn piglet. Reprod. Fertil. Dev. 25:1126-1133. https://doi.org/10.1071/ RD12103.

Caperna, T. J., A. E. Shannon, M. Stoll, S. Kahl, L. A. Blomberg, J. L. Vallet, and T. G. Ramsay. 2017. A sandwich ELISA for porcine $\alpha-1$ acid glycoprotein (pAGP, ORM-1) and further demonstration of its use to evaluate growth potential in newborn pigs. Domest. Anim. Endocrinol. 60:75-82. https://doi.org/10.1016/j.domaniend 2017.04.001.

Carpenter, A. J., C. M. Ylioja, L. K. Mamedova, K. E. Olagaray, and B. J. Bradford. 2018. Effects of early postpartum sodium salicylate treatment on long-term milk, intake, and blood parameters of dairy cows. J. Dairy Sci. 101:1437-1447. https://doi.org/10.3168/ jds.2017-13057.

Ceciliani, F., J. J. Ceron, P. D. Eckersall, and H. Sauerwein. 2012. Acute phase proteins in ruminants. J. Proteomics 75:4207-4231. https://doi.org/10.1016/j.jprot.2012.04.004.

Ceciliani, F., and C. Lecchi. 2019. The immune functions of $\alpha_{1}$ acid glycoprotein. Curr. Protein Pept. Sci. 20:505-524. https://doi.org/ 10.2174/1389203720666190405101138.

Clapperton, M., S. C. Bishop, N. D. Cameron, and E. J. Glass. 2005. Associations of acute phase protein levels with growth performance and with selection for growth performance in Large White pigs. Anim. Sci. 81:213-220. https://doi.org/10.1079/ASC50180213.

Clapperton, M., S. C. Bishop, M. Piñeiro, F. M. Campbell, and E. J. Glass. 2007. The association between plasma levels of acute phase proteins, haptoglobin, $\alpha-1$ acid glycoprotein (AGP), Pig-MAP, transthyretin and serum amyloid A (SAA) in Large White and Meishan pigs. Vet. Immunol. Immunopathol. 119:303-309. https:/ /doi.org/10.1016/j.vetimm.2007.05.008.

Dubuc, J., and J. Denis-Robichaud. 2017. A dairy herd-level study of postpartum diseases and their association with reproductive performance and culling. J. Dairy Sci. 100:3068-3078. https://doi .org/10.3168/jds.2016-12144.

Eckersall, P. D., F. P. Lawson, L. Bence, M. M. Waterston, T. L. Lang, W. Donachie, and M. C. Fontaine. 2007. Acute phase protein response in an experimental model of ovine caseous lymphadenitis. BMC Vet. Res. 3:35. https://doi.org/10.1186/1746-6148-3-35.

Ehrhardt, R. A., A. Foskolos, S. L. Giesy, S. R. Wesolowski, C. S. Krumm, W. R. Butler, S. M. Quirk, M. R. Waldron, and Y. R. Boisclair. 2016. Increased plasma leptin attenuates adaptive metabolism in early lactating dairy cows. J. Endocrinol. 229:145-157. https://doi.org/10.1530/JOE-16-0031.

Esposito, G., P. C. Irons, E. C. Webb, and A. Chapwanya. 2014. Interactions between negative energy balance, metabolic diseases, uterine health and immune response in transition dairy cows. Anim. Reprod. Sci. 144:60-71. https://doi.org/10.1016/j.anireprosci.2013 .11 .007 .
Fournier, T., N. Medjoubi-N, and D. Porquet. 2000. $\alpha-1-$ Acid glycoprotein. Biochim. Biophys. Acta 1482:157-171. https://doi.org/10 .1016/S0167-4838(00)00153-9.

Gardner, I. A., and M. Greiner. 2006. Receiver-operating characteristic curves and likelihood ratios: Improvements over traditional methods for the evaluation and application of veterinary clinical pathology tests. Vet. Clin. Pathol. 35:8-17. https://doi.org/10 $.1111 /$ j.1939-165X.2006.tb00082.x.

Gregg, B. A., P. A. Parker, K. M. Waller, L. G. Schneider, M. Garcia, B. Bradford, J. A. Daniel, and B. K. Whitlock. 2019. Effects of central and peripheral administration of an acute-phase protein, $\alpha$-1-acid-glycoprotein, on feed intake and rectal temperature in sheep. J. Anim. Sci. 97:4783-4791. https://doi.org/10.1093/jas/ skz336.

Hajian-Tilaki, K. 2014. Sample size estimation in diagnostic test studies of biomedical informatics. J. Biomed. Inform. 48:193-204. https://doi.org/10.1016/j.jbi.2014.02.013.

Henry, B. A., J. W. Goding, A. J. Tilbrook, F. R. Dunshea, and I. J. Clarke. 2001. Intracerebroventricular infusion of leptin elevates the secretion of luteinising hormone without affecting food intake in long-term food-restricted sheep, but increases growth hormone irrespective of bodyweight. J. Endocrinol. 168:67-77. https://doi .org/10.1677/joe.0.1680067.

Hochepied, T., F. G. Berger, H. Baumann, and C. Libert. 2003. Alpha(1)-acid glycoprotein: An acute phase protein with inflammatory and immunomodulating properties. Cytokine and Growth Factor Reviews 14:25-34.

Hochepied, T., W. Van Molle, F. G. Berger, H. Baumann, and C. Libert. 2000. Involvement of the acute phase protein $\alpha 1$-acid glycoprotein in nonspecific resistance to a lethal Gram-negative infection. J. Biol. Chem. 275:14903-14909. https://doi.org/10.1074/jbc .275.20.14903

Horadagoda, N. U., K. M. G. Knox, H. A. Gibbs, S. W. J. Reid, A. Horadagoda, S. E. R. Edwards, and P. D. Eckersall. 1999. Acute phase proteins in cattle: discrimination between acute and chronic inflammation. Vet. Rec. 144:437-441. https://doi.org/10.1136/vr .144.16.437.

Humblet, M.-F., H. Guyot, B. Boudry, F. Mbayahi, C. Hanzen, F. Rollin, and J.-M. Godeau. 2006. Relationship between haptoglobin, serum amyloid A, and clinical status in a survey of dairy herds during a 6-month period. Vet. Clin. Pathol. 35:188-193. https:// doi.org/10.1111/j.1939-165X.2006.tb00112.x.

Huzzey, J. M., S. Mann, D. V. Nydam, R. J. Grant, and T. R. Overton. 2015. Associations of peripartum markers of stress and inflammation with milk yield and reproductive performance in Holstein dairy cows. Prev. Vet. Med. 120:291-297. https://doi.org/10.1016/ j.prevetmed.2015.04.011.

Huzzey, J. M., D. V. Nydam, R. J. Grant, and T. R. Overton. 2011. Associations of prepartum plasma cortisol, haptoglobin, fecal cortisol metabolites, and nonesterified fatty acids with postpartum health status in Holstein dairy cows. J. Dairy Sci. 94:5878-5889. https://doi.org/10.3168/jds.2010-3391.

Jafari, A., D. G. V. Emmanuel, R. J. Christopherson, J. R. Thompson, G. K. Murdoch, J. Woodward, C. J. Field, and B. N. Ametaj. 2006. Parenteral administration of glutamine modulates acute phase response in postparturient dairy cows. J. Dairy Sci. 89:4660-4668. https://doi.org/10.3168/jds.S0022-0302(06)72516-4.

Janovick, N. A., Y. R. Boisclair, and J. K. Drackley. 2011. Prepartum dietary energy intake affects metabolism and health during the periparturient period in primiparous and multiparous Holstein cows 1. J. Dairy Sci. 94:1385-1400. https://doi.org/10.3168/jds .2010-3303.

Leno, B. M., S. E. LaCount, C. M. Ryan, D. Briggs, M. Crombie, and T. R. Overton. 2017a. The effect of source of supplemental dietary calcium and magnesium in the peripartum period, and level of dietary magnesium postpartum, on mineral status, performance, and energy metabolites in multiparous Holstein cows. J. Dairy Sci. 100:7183-7197. https://doi.org/10.3168/jds.2017-12773.

Leno, B. M., C. M. Ryan, T. Stokol, D. Kirk, K. P. Zanzalari, J. D. Chapman, and T. R. Overton. 2017b. Effects of prepartum dietary cation-anion difference on aspects of peripartum mineral and en- 
ergy metabolism and performance of multiparous Holstein cows. J. Dairy Sci. 100:4604-4622. https://doi.org/10.3168/jds.2016-12221.

Lewis, E. J., J. Bishop, and C. H. Cashin. 1989. Automated quantification of rat plasma acute phase reactants in experimental inflammation. J. Pharmacol. Methods 21:183-194. https://doi.org/10 .1016/0160-5402(89)90053-3.

Libert, C., P. Brouckaert, and W. Fiers. 1994. Protection by a1-acid glycoprotein against tumor necrosis factor-induced lethality. J. Exp. Med. 180:1571-1575. https://doi.org/10.1084/jem.180.4 .1571 .

Liefers, S. C., R. F. Veerkamp, M. F. W. Te Pas, C. Delavaud, Y. Chilliard, and T. Van Der Lende. 2003. Leptin concentrations in relation to energy balance, milk yield, intake, live weight, and estrus in dairy cows. J. Dairy Sci. 86:799-807. https://doi.org/10 .3168/jds.S0022-0302(03)73662-5.

Ling, P. R., J. H. Schwartz, M. Jeevanandam, J. Gauldie, and B. R. Bistrian. 1996. Metabolic changes in rats during a continuous infusion of recombinant interleukin-1. Am. J. Physiol. 270:E305-E312. https://doi.org/10.1152/ajpendo.1996.270.2.E305.

McCarthy, M. M., T. Yasui, M. J. B. Felippe, and T. R. Overton. 2016. Associations between the degree of early lactation inflammation and performance, metabolism, and immune function in dairy cows. J. Dairy Sci. 99:680-700. https://doi.org/10.3168/jds.2015-9694.

McGuckin, M. M., S. L. Giesy, A. N. Davis, M. A. Abyeta, E. A. Horst, S. Saed Samii, Y. Zang, W. R. Butler, L. H. Baumgard, J. W. Mcfadden, and Y. R. Boisclair. 2020. The acute phase protein orosomucoid 1 is upregulated in early lactation but does not trigger appetite-suppressing STAT3 signaling via the leptin receptor. J. Dairy Sci. 103:4765-4776. https://doi.org/10.3168/jds.2019 $-18094$.

McLaren, C. J., K. D. Lissemore, T. F. Duffield, K. E. Leslie, D. F. Kelton, and B. Grexton. 2006. The relationship between herd level disease incidence and a return over feed index in Ontario dairy herds. Can. Vet. J. 47:767-773.

Mooney, P., P. Hayes, and K. Smith. 2006. The putative use of alpha1-acid glycoprotein as a non-invasive marker of fibrosis. Biomed. Chromatogr. 20:1351-1358. https://doi.org/10.1002/bmc.704.

Morrison, C. D., J. A. Daniel, B. J. Holmberg, J. Djiane, N. Raver, A. Gertler, and D. H. Keisler. 2001. Central infusion of leptin into well-fed and undernourished ewe lambs: Effects on feed intake and serum concentrations of growth hormone and luteinizing hormone. J. Endocrinol. 168:317-324. https://doi.org/10.1677/joe .0 .1680317 .

Olagaray, K. E., S. E. Sivinski, B. A. Saylor, L. K. Mamedova, J. A. Sauls-Hiesterman, I. Yoon, and B. J. Bradford. 2019. Effect of Saccharomyces cerevisiae fermentation product on feed intake parameters, lactation performance, and metabolism of transition dairy cattle. J. Dairy Sci. 102:8092-8107. https://doi.org/10.3168/ jds.2019-16315.

Schwartz, M. W., S. C. Woods, D. Porte Jr., R. J. Seeley, and D. G. Baskin. 2000. Central nervous system control of food intake. Nature 404:661-671. https://doi.org/10.1038/35007534.

Sheldon, I. M., D. E. Noakes, A. Rycroft, and H. Dobson. 2001. Acute phase protein responses to uterine bacterial contamination in cat- tle after calving. Vet. Rec. 148:172-175. https://doi.org/10.1136/ vr.148.6.172.

Smith, J. W., L. O. Ely, and A. M. Chapa. 2000. Effect of region, herd size, and milk production on reasons cows leave the herd. J. Dairy Sci. 83:2980-2987. https://doi.org/10.3168/jds.S0022 $-0302(00) 75198-8$.

Sun, Y., Y. Yang, Z. Qin, J. Cai, X. Guo, Y. Tang, J. Wan, D. F. Su, and X. Liu. 2016. The acute-phase protein orosomucoid regulates food intake and energy homeostasis via leptin receptor signaling pathway. Diabetes 65:1630-1641. https://doi.org/10.2337/db15 $-1193$.

Trevisi, E., M. Amadori, A. M. Bakudila, and G. Bertoni. 2009. Metabolic changes in dairy cows induced by oral, low-dose interferonalpha treatment. J. Anim. Sci. 87:3020-3029. https://doi.org/10 $.2527 /$ jas. 2008-1178.

Williams, N. H., T. S. Stahly, and D. R. Zimmerman. 1997a. Effect of level of chronic immune system activation on the growth and dietary lysine needs of pigs fed from 6 to $112 \mathrm{~kg}$. J. Anim. Sci. 75:2481-2496. https://doi.org/10.2527/1997.7592481x.

Williams, N. H., T. S. Stahly, and D. R. Zimmerman. 1997b. Effect of chronic immune system activation on the rate, efficiency, and composition of growth and lysine needs of pigs fed from 6 to $27 \mathrm{~kg}$. J. Anim. Sci. 75:2463-2471. https://doi.org/10.2527/1997.7592463x.

Wong, S., and J. Pinkney. 2004. Role of cytokines in regulating feeding behaviour. Curr. Drug Targets 5:251-263. https://doi.org/10 $.2174 / 1389450043490532$.

Yuan, K., J. K. Farney, L. K. Mamedova, L. M. Sordillo, and B. J. Bradford. 2013. TNFo altered inflammatory responses, impaired health and productivity, but did not affect glucose or lipid metabolism in early-lactation dairy cows. PLoS One 8:e80316. https://doi .org/10.1371/journal.pone.0080316.

Zenobi, M. G., R. Gardinal, J. E. Zuniga, A. L. G. Dias, C. D. Nelson, J. P. Driver, B. A. Barton, J. E. P. Santos, and C. R. Staples 2018. Effects of supplementation with ruminally protected choline on performance of multiparous Holstein cows did not depend upon prepartum caloric intake. J. Dairy Sci. 101:1088-1110. https://doi .org/10.3168/jds.2017-13327.

\section{ORCIDS}

W. E. Brown (ํ) https://orcid.org/0000-0002-8457-7741 M. Garcia @ https://orcid.org/0000-0001-6247-9385

L. K. Mamedova () https://orcid.org/0000-0003-3612-0381

C. R. Staples $\odot$ https://orcid.org/0000-0002-0237-946X

B. M. Leno (1) https://orcid.org/0000-0003-0839-1424

T. R. Overton (๑) https://orcid.org/0000-0003-4098-4916

B. K. Whitlock @ https://orcid.org/0000-0001-7247-0982

J. A. Daniel @ https://orcid.org/0000-0001-8309-4572

B. J. Bradford ๑ https://orcid.org/0000-0002-6775-4961 